\title{
Academic success is about self-efficacy rather than frequency of use of the learning management system
}

\author{
Dr Jaclyn Broadbent \\ School of Psychology \\ Fellow, Centre for Research in Assessment and Digital Learning \\ Deakin University
}

\begin{abstract}
Previous studies have investigated the association between the frequency of student learning management system (LMS) use (logins, discussion board use, resources used, etc.) and academic achievement. These studies indicate that low LMS use by students is likely to result in less academic success. However, these models fail to take into account self-beliefs that may also increase the explanatory value of learning analytics from the LMS. This study surveyed 310 students $(M=22.10$ years, $S D=6.30$ years $)$ undertaking a first year health psychology subject. Results show the central role of self-efficacy in predicting student performance. Online activity was not predictive of performance, suggesting the primacy of psychological factors more so than online engagement in determining outcome. Of the motivational factors, amotivation was the single significant predictor of academic achievement. Proposed future research directions include the need to evaluate whether these results are sustained over time.
\end{abstract}

\section{Introduction}

The introduction of learning management systems (LMS) has shaped the landscape of higher education, allowing the transformation of traditional face-to-face classrooms to that of blended and online educational environments (Beer, Clark, \& Jones, 2010). The use of LMS (e.g., Brightspace by D2L, Moodle, and Blackboard) has allowed for various modes of interaction, asynchronous and synchronous learning, increased flexibility, and the development of web-based pedagogical tools (Beer et al., 2010; Coates, James, \& Baldwin, 2005; Dabbagh \& Bannan-Ritland, 2005). Thus, the use of the LMS has had a significant impact on the way in which students engage in the learning process (Beer et al., 2010; Coates et al., 2005).

\section{Literature review}

Previously, student engagement was measured using proxies such as class attendance. More recently, measures of engagement include data obtained from the LMS known as learning analytics (Beer et al., 2010). Learning analytics can be defined as "the measurement, collection, analysis and reporting of data about learners and their contexts, for purposes of understanding and optimizing learning and the environments in which it occurs” (Society for Learning Analytics Research [SOLAR], 2012). Measuring student behaviours through learning analytics allows researchers to examine relationships between students' LMS use and grade performance (Caruso, 2006). Student behaviours on the LMS, such as, (1) number of logins, (2) time spent online, (3) number interactions with the discussion boards, and (4) and use of resources, are all related with academic performance (Gašević, Dawson, \& Siemens, 2015; Gašević, Mirriahi, Long, \& Dawson, 2014).

However, research using LMS student activity data often overlooks other fundamental aspects that influence student engagement, not mined from the LMS. Other factors such as student self-efficacy (SE), motivation, and control have been found to be good independent predictors of academic success (Honicke \& Broadbent, 2016; Richardson, Bond, \& Abraham, 2012; Robbins, Lauver, Le, David, \& Langley, 2004). Including psychosocial factors alongside learning analytics in the prediction of academic success is important, as these factors are malleable and thus amenable to intervention (Robbins et al., 2004).

Within the context of education, SE is defined as learner judgments about their ability to successfully achieve educational goals (Elias \& MacDonald, 2007). Self-efficacy influences the amount of effort students exert, their persistence in the face of difficulties, and their resilience to setbacks in goal attainment (Zimmerman, Bandura, \& Martinez-Pons, 1992). Three recent systematic reviews (cf. Honicke \& 
Broadbent, 2016; Richardson et al., 2012; Robbins et al., 2004) show that SE consistently correlates and robustly predicts academic achievement.

Like SE, academic motivation has been shown to direct a student's behaviour toward the fulfilment of academic success (Pintrich \& Schunk, 1996). Although a number of different models exist to explain motivation within achievement motivation research (Pintrich, Conley, \& Kemplar, 2004), perhaps the most commonly accepted framework characterises motivation into two parts: intrinsic and extrinsic motivation (Deci \& Ryan, 1985).

Intrinsic motivation focuses on gaining mastery and skill over learning for its own purpose, rather than the outcome that it may produce (Neuville, Frenay, \& Bourgeois, 2007). For example, an intrinsically orientated student may direct their learning to subject topics that they find interesting and fulfilling, rather than be driven by improvement in their grades. Extrinsic motivation, on the other hand, focuses on performance outcomes and out-performing others, rather than learning for its own purpose (Deci \& Ryan, 1985). For example, an extrinsically orientated student is more likely to focus on study behaviours that result in outcomes such as approval from others, winning awards, or the attainment of high marks. Students who are neither intrinsically nor extrinsically motivated are classified as amotivated (Deci \& Ryan, 1985). These students cannot perceive the relationship between their behaviours and the subsequent outcome (Deci \& Ryan, 1985). They experience a lack of control and feelings of incompetence, learned helplessness, and may feel coerced into study (Guay, Ratelle, Roy, \& Litalien, 2010; Legault, Green-Demers, \& Pelletier, 2006).

Past research indicates that intrinsic motivation is a better predictor of academic success than extrinsic motivation (Richardson et al., 2012) and that students who are intrinsically motivated have higher levels of SE (Friedal, Cortina, Turner, \& Midgley, 2007), which in turn is related to higher academic achievement (Diseth, 2011; Middleton \& Midgley, 1997). In contrast, those who are extrinsically motivated usually have lower levels of SE (Friedal et al., 2007), with studies reporting mixed findings regarding the relationship between academic achievement, SE, and extrinsic motivation (Bong, 2005; Harackiewicz, Barron, Tauer, Carter, \& Elliot, 2000). High amotivation has also been associated with lower SE (Turner, Chandler, \& Heffer, 2009), poorer academic success (Vanthournout, Gijbels, Coertjens, Donche, \& Van Petegem, 2012), and feeling that a behaviour is beyond one's control (Legault et al., 2006).

Lastly, a person's beliefs about control over life events can also play a role in academic success. This control can be, (1) internal - with students perceiving events to be contingent upon their own behavior such as believing a grade is reflective of the amount of work they put in, or (2) external - with students perceiving events are determined by forces beyond their control, such as the result of luck, fate or powerful others such as believing a grade is reflective of whether the teacher likes them or not (Rotter, 1966). An external locus of control has been associated with higher dropout rates and lower academic success (Gifford, BricenoPerriott, \& Mianzo, 2006). Internal locus of control, on the other hand, is positively associated with academic achievement (Gifford et al., 2006), better study strategies, resulting in great academic success (Cassidy \& Eachus, 2000), more pride in course performance (Schonwetter, Perry, \& Struthers, 1993), and less dropout (Perry, Hladkyj, Pekrun, \& Pelletier, 2001. Given the level of autonomy and self-directed learning that is required in a university setting, having a high internal locus of control is beneficial (Perry, 2003).

There is evidence of a positive relationship between high levels of SE, high levels of motivation, and an internal locus of control and academic achievement (Harter, 1981; Schneider, Borkowski, Kurtz, \& Kerwin, 1986). Although the accumulated literature suggests that these variables are related, few if any studies have tested the plausibility of a model that predicts directional paths of all these variables at once. Also, and as discussed earlier, engagement has typically been measured indirectly rather than with objective, computerbased data that may more reliably indicate level of engagement of students. Hence, the present study tests a model, informed by proposed risk factors and their potential inter-relations, for predicting academic performance. Such a model may help to piece together the direction of effects (and the relative contributions of proposed risk factors), and in turn, this may help with prioritising areas for improvement to ensure academic performance of university students. Figure 1 shows the predicted pathways for the hypothesised model. 


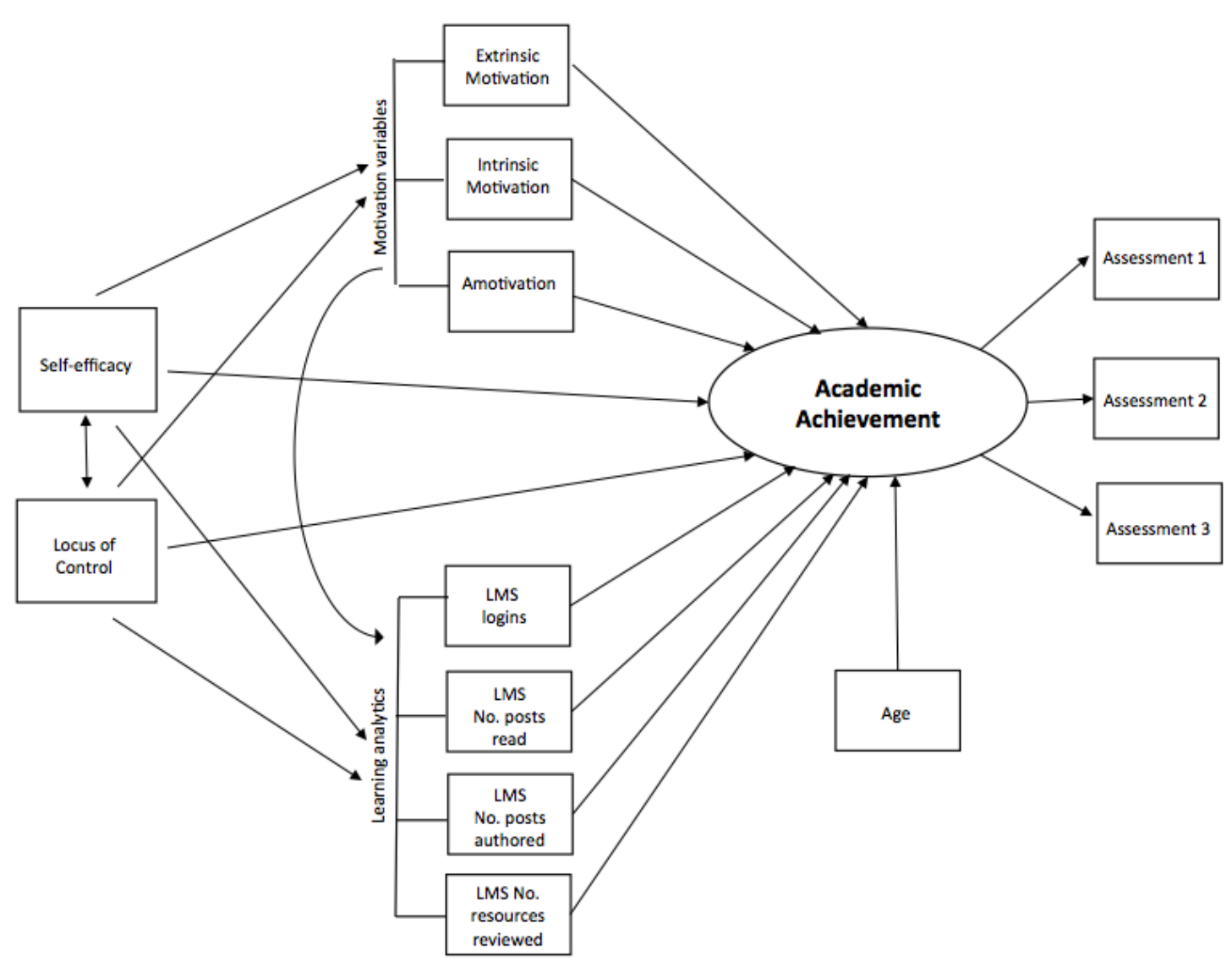

Figure 1. Path diagram of predicted pathways of hypothesised model

\section{Hypotheses}

1. Students' age, motivation (intrinsic, extrinsic and amotivation), self-efficacy, locus of control and learning analytics (LMS logins, number posts read, number posts authored and number resources reviewed) predict academic achievement (grade) based on the hypothesised model.

2. Students academic achievement will be higher with:
a. higher self-efficacy
b. higher levels of Intrinsic motivation, and / or extrinsic motivation
c. lower amotivation
d. an internal locus of control
e. greater use of the LMS

3. Student's self-efficacy, motivation, locus of control and learning analytics interact.

\section{Method}

\section{Participants}

The participants were 310 students undertaking a first-year health psychology subject at an Australian university. Participants' ages ranged from 18 to 50 years $(M=22.10$ years, $S D=6.30$ years $)$. The majority of participants were female (88\%) and in first year of their undergraduate degree (83\%). The remaining students were in second year (14\%), third year (2\%), or did not report which year of their undergraduate degree they were completing (1\%). Enrolment status was not recorded, however, students could be enrolled as either online or blended mode. The main point of difference was blended students were able to attend face-to-face lectures and tutorials if they chose, while online students could attend online live lectures and tutorials or watch the recordings. The latter option was also available for blended students. All other unit resources and information were disseminated via the same LMS site for both cohorts. 


\section{Materials}

Academic performance

Academic performance was measured by official end of semester grades for the subject. The end of semester grade was made up of three assessment pieces. Assessment 1 was 10 online quizzes worth $10 \%$, Assessment 2 was 4 online reflective journals worth $45 \%$ and spread across the trimester, and Assessment 3 was an end-of-semester exam worth $45 \%$ and contained 100 multiple choice questions.

Self-efficacy

The 21-item Academic Self-Efficacy Scale (ASES) (Abesha, 2012) consists of four SE subscales: (1) interaction at university; (2) performance out of university; (3) performance in university; and (4) managing work, family, and university. All were assessed on a four-point Likert scale ranging from strongly disagree (1) to strongly agree (4). Scores for each subscale were summed to yield an overall self-efficacy score, which ranged from 21 to 84 . A higher score represented higher self-confidence. The scale was found to have a high internal reliability in the present study $(\alpha=.89)$.

Locus of control

Trice's (1985) Academic Locus of Control scale was used to measure student beliefs regarding their personal control over academic outcomes. This measure includes 28 true or false items, which were modified to fit the Australian educational context. Words making reference to "college" or "professors" were substituted with "university” and "lecturer”, respectively. For example, "[University] grades most often reflect the effort you put into classes" ("University” replaced the word "College”). Higher scores represent higher external locus of control (belief that academic outcomes are not within the individual's control), while lower scores represent higher internal locus of control (belief that academic outcomes are within the individual's control). The scale exhibited acceptable internal reliability in the present study ( $\alpha=$ .71).

\section{Motivation}

Motivation was measured using the Academic Motivation Scale (Vallerand \& Bissonnette, 1992). The scale consists of 28 items, which make up three subscales assessing: (1) intrinsic motivation, (2) extrinsic motivation, and (3) amotivation. Each item is rated on a seven-point Likert scale ranging from 1 (does not correspond) to 7 (corresponds exactly). The intrinsic motivation subscale contains 12 items relating to intrinsic motivations to know, towards accomplishments, and to experience stimulation, with overall scores ranging from 12 to 84 . The extrinsic motivation subscale contains 12 items relating to external regulation, introjection regulation, and identification, and overall scores range from 12 to 84 . Lastly, the amotivation subscale contains 4 items related to being neither intrinsically or extrinsically. Overall scores range from 4 to 28, with higher scores indication higher intrinsic motivation, extrinsic motivation or amotivation. The scale was found to have high internal reliability in the present study $(\alpha=.90)$.

Learning analytics from the LMS (Brightspace by D2L)

Three measures were taken at the end of the semester to assess engagement with the LMS: (1) the number of times the student had logged on to the LMS over the course of the approximately 12 week semester; (2) the number of discussion posts read; (3) the number of discussion threads authored; and (4) the number of resources reviewed.

\section{Procedure}

Participants were recruited through announcements made in the subject's lectures, Facebook group page, and LMS, with a link to an online questionnaire. The questionnaire took approximately 30 minutes to complete and was made available for students to complete at their leisure, at any point from week 11 of the 12-week semester until their exam - a period of approximately 5 weeks. Collection of final grades and learning analytics occurred once final results had been released at the end of the semester. 


\section{Results}

Correlational analyses using SPSS Version 20 were performed to examine the interrelationships between the psychological factors, learning analytics, and grade outcomes. Path analysis - with robust standard errors to control for outliers and issues of non-normality - was implemented using Mplus to test the significant relationships between variables in the correlation matrix. Table 1 displays the correlation matrix and descriptive statistics.

From Table 1, self-efficacy was found to have a significant weak positive relationship with academic achievement. Locus of control and amotivation were both found to have a significant weak negative relationship with academic achievement. No other variables were directly associated with academic achievement.

The model fit was measured using chi-square goodness-of-fit statistic, the chi-square divided by degrees of freedom $\left(\chi^{2} / d f\right)$ (good fit $<3$ ), the comparative fit index (CFI) (good fit $>.95$, acceptable fit $\left.>.90\right)(\mathrm{Hu} \&$ Bentler, 1999), root mean square error of approximation (RMSEA) (good fit $<.06$, acceptable fit $<.08$ ) (Hu \& Bentler, 1999), and the standardised root mean square residual (SRMR) (good fit $<.05$, acceptable fit < .08) (Hu \& Bentler, 1999).

While the intended model had reasonable fit $\left(\chi^{2}{ }_{(29)}=103.89, p<.001, \chi^{2} / d f=3.58\right.$, CFI $=.92$ and RMSEA $=.09$, SRMR = .06), modification indices suggested the need to co-vary age with intrinsic motivation and locus of control. This revised model had good fit $\left(\chi_{(27)}^{2}=76.14, p<.001, \chi^{2} / d f=2.8\right.$, CFI $=.95$ and RMSEA $=.08$, SRMR $=.05)$. Within the path model, 2 directional pathways and 21 co-variances were significant. The reported values in Figure 2 are the significant standardised regression weights of the model ( $\beta$, beta weights). Non-significant pathways were omitted from Figure 2 to enhance readability, but are available upon request from the author. The model accounted for $14.1 \%$ of the variance in academic performance ( $p$ $<.01)$.

Students' total SE was a significant positive predictor of their overall academic achievement for the subject $(\beta=.20, p<.01)$, and a significant positive predictor of intrinsic $(\beta=.29, p<.001)$ and extrinsic motivation $(\beta=.13, p<.05)$. Self-efficacy and locus of control were significantly related to each other $(\beta=-.36, p<$ .001), showing that students with higher SE also had stronger internal locus of control.

Students' internal locus of control significantly correlated with greater number of LMS logins $(\beta=-.17, p$ $<.01)$, a greater number of LMS resources reviewed $(\beta=-.11, p<.05)$, were more intrinsically motivated $(\beta=-.10, p<.05)$, and older $(\beta=-.21, p<.001)$. However, students with an external locus of control were more likely to read more LMS discussion posts $(\beta=.11, p<.05)$, and be amotivated $(\beta=.41, p<.001)$. Locus of control was not significantly predictive of students' overall academic achievement.

Students with lower amotivation were less academically successful $(\beta=-.13, p<.05)$, and read less discussion posts $(\beta=-.16, p<.01)$. Students who were intrinsically motivated however were more likely to report extrinsic sources of motivation as well $(\beta=.40, p<.001)$, reviewed more resources on the LMS $(\beta=.12, p<.05)$, logged on to the LMS more often $(\beta=.18, p<.01)$ and were older $(\beta=.17, p<.001)$. Extrinsically motivated students were less likely to read discussion posts $(\beta=-.10, p<.05)$.

Lastly, students who logged in to the LMS more often also authored more discussion posts $(\beta=.13, p<$ $.05)$, viewed more resources $(\beta=.86, p<.001)$, and read more discussion posts $(\beta=.36, p<.001)$. Those who read more posts also reviewed more resources $(\beta=.38, p<.001)$ and authored more posts $(\beta=.34, p$ $<.001)$. Those who authored more posts also reviewed more resource $(\beta=.10, p<.05)$. 


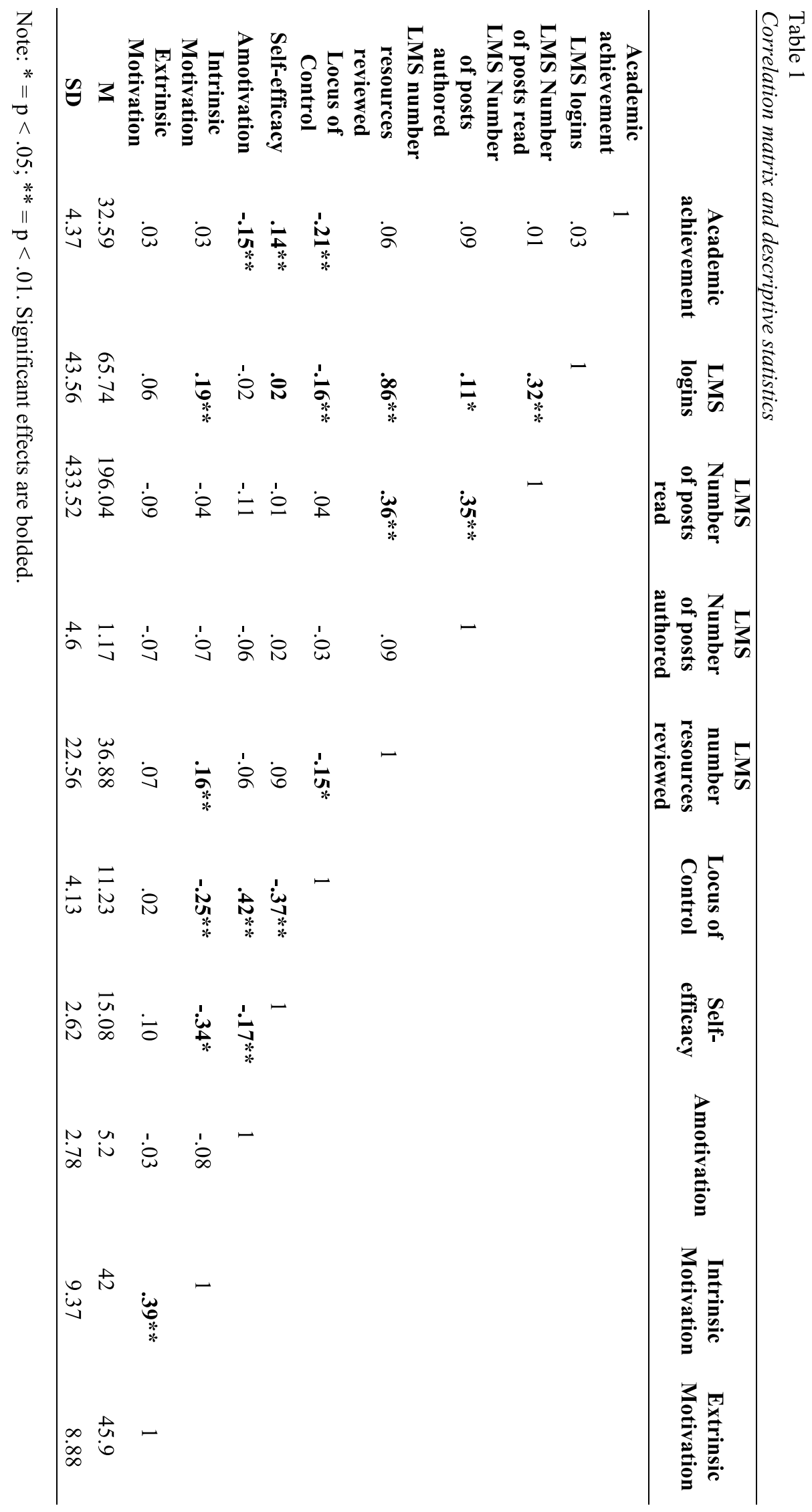




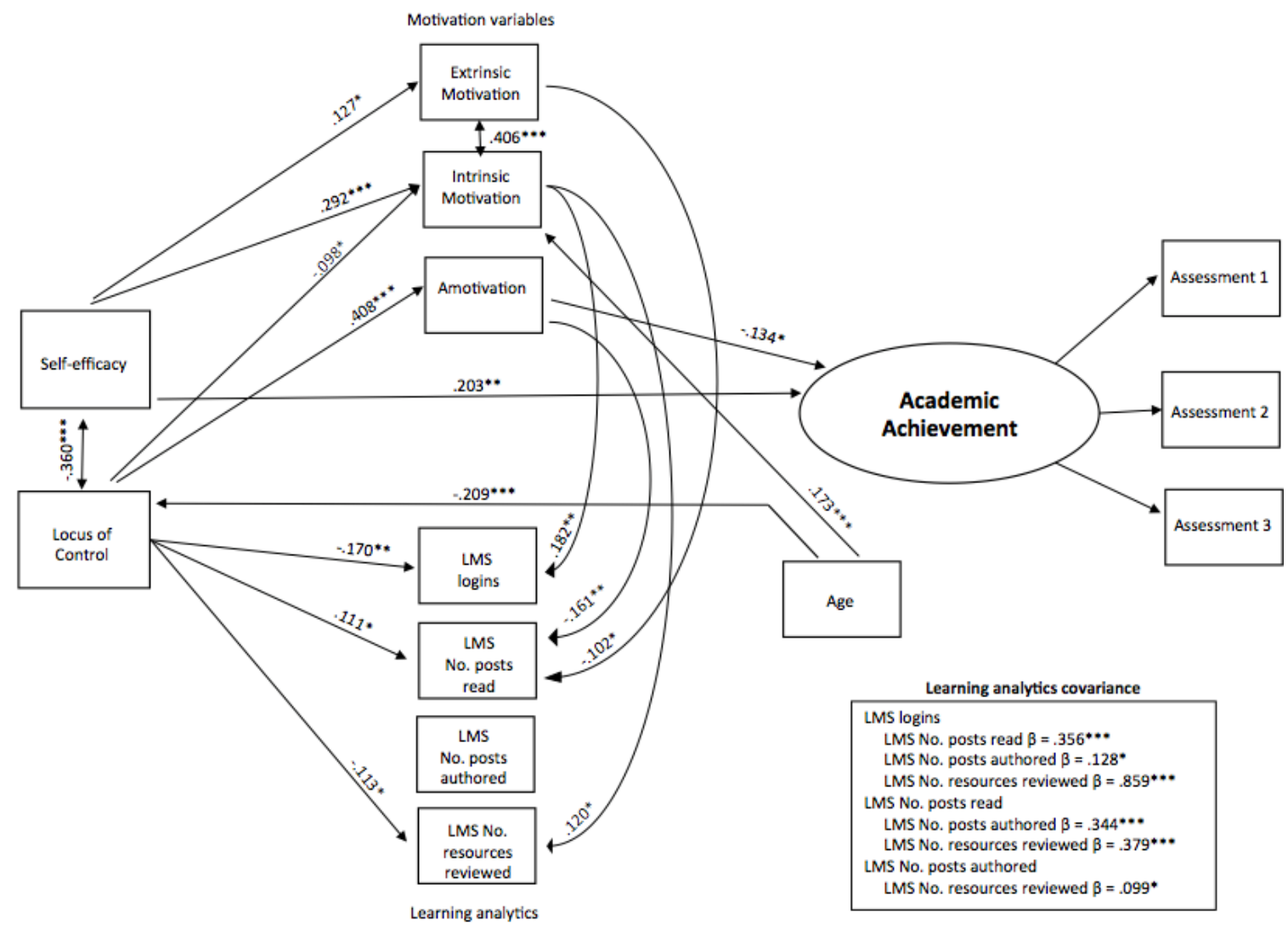

Figure 2. Path diagram of pathways

Note: $*=\mathrm{p}<.05 ; * *=\mathrm{p}<.01 ; * * *=\mathrm{p}<.001$

\section{Discussion}

Previous studies have investigated the association between the frequency of student LMS use (logins, discussion board use, resources used, etc.) and academic achievement (Gašević et al., 2015; Gašević et al 2014). These studies indicate that low LMS use by students is likely to result in less academic success. However, these models fail to take into account self-beliefs that may also increase the explanatory value of learning analytics from the LMS.

In the present study, only two psychosocial variables and none of the learning analytic variables directly predicted academic achievement. Of these, SE was the strongest direct predictor of academic achievement. Amotivation also directly predicted academic success. Although locus of control, intrinsic and extrinsic motivation were related to SE, none of these variables directly predicted the students' academic success.

Self-efficacy has consistently been shown to positively correlate with and robustly predict academic performance, with meta-analytic studies reporting moderate to large effect sizes (Honicke \& Broadbent, 2016; Richardson et al., 2012; Robbins et al., 2004). It is not surprising therefore that SE was strongly related to academic achievement in the present study. Students who have high levels of self-belief in their ability to achieve academically are more likely to experience academic success. Highly self-efficacious students are more likely to set higher goals for themselves and have greater commitment to their studies (Bandura, 1991). This finding alone has several implications for educators involved in the development and implementation of student courses. Specifically, courses should promote learning environments that foster approaches that build confidence to learn: mastery of experience, verbal persuasion, vicarious experience and physiological states (Bandura, 1997); and consider how the delivery of course material and feedback can result in increased levels of academic SE. 
While SE was found to be one of two predictors of academic success in the current study, a meta-analysis conducted by Robbins et al. (2004) suggests ASE beliefs account for up to $14 \%$ variance in university student GPA. This implies other significant factors exist to explain the variation in academic achievement of university students. Indeed, the present study showed a robust relationship with intrinsic motivation, indicating that those students who were highly confident about their studies were also focused on gaining mastery over learning. This makes sense given the tendency for those who are intrinsically motivated to demonstrate perseverance amidst adversity and have greater levels of self-belief to successfully complete tasks (Ames \& Archer, 1988; Friedal et al., 2007). This finding is consistent with previous research findings, which report strong positive relationships between intrinsic motivation and SE (Coutinho \& Neuman, 2008; Diseth, 2011). Further, SE had a positive relationship with extrinsic motivation, so despite also wanting to gain mastery over the task, these students had a dual focus on performance outcomes such as grade. Lastly, SE had a strong negative relationship with locus of control, indicating that individuals who did not have confidence in their own abilities to succeed were also more likely to believe that academic success was outside of their control, and influenced by external forces.

In line with previous research, amotivation was found to have a direct, negative relationship with academic success (Turkmen, 2013; Turner et al., 2009). Amotivation is a type of motivation where the student does not see a relationship between his or her own actions and academic outcomes. Students who are amotivated feel incompetent, expect to be unable to achieve a desired outcome (Seligman, 1975), and expect their environment to be uncontrollable (Vallerand \& Bissonnette, 1992). It is unsurprising therefore that students in the present study with high levels of amotivation also displayed an external locus of control. That is, if they felt their actions were not directly related to their grade, they also felt that forces outside of their control (perhaps a teacher who does not like them) contributed to their academic success. Given this, it also makes sense that they were less motivated to read discussion board posts by other students. Vallerand and Bissonnette (1992) contends that amotivated students question why they bother attending university, and are likely to stop engaging in academic-related behaviours. Partially, this lack of motivation relates to feelings regarding their ability to perform the actions needed to obtain the academic goal (Vanthoournout et al., 2012) and result in increased academic drop-out rates and academic disengagement (Vallerand, Fortier, \& Guay, 1997). This has important implications for student success. Targeted approaches could be used to increase academic motivation. Teachers in particular have been shown to be an important source of academic information and, through feedback, could be used to stimulate academic motivation (Legault et al., 2006). Parents, on the other hand, have been shown to be an importance influence over academic value and should be encouraged to place high importance on the value in academic studies (Legault et al., 2006).

Unexpectedly, both intrinsic and extrinsic motivation while strongly related to one another, were not directly related to academic achievement. This indicates that level of motivation, whether driven by grade or learning goals, was not a direct predictor of grade in the current study. Meta-analytic results show that while studies of academic achievement have found that students' extrinsic motivation is not related to grade, intrinsic motivation has been (Richardson et al., 2012). Possibly, SE is a more important than source of motivation for academic performance.

Lastly, learning analytics in the form of LMS log in frequency, use of resources, and discussion posts read and authored surprisingly did not predict academic success. This is contrary to much of the extant literature, in which behaviours such as actively participating in the discussion forums and downloading the resources increase the chance of academic success (Carceller, Dawson, \& Lockyer, 2013; ChanLin, 2012; Broadbent \& Poon, 2015; Michinov, Brunot, Le Bohec, Juhel, \& Delaval, 2011). While the learning analytics had strong relationships amongst themselves - which is to be expected - level of self-efficacy did not impact on how often students used the LMS, illustrating that in this instance both academically confident and unconfident students used the LMS equally frequently. This implies that low LMS usage should not be used as a red flag to indicate diminished confidence nor diminished likelihood of academic success. Conversely, use of the LMS alone may not be sufficient for academic performance, and students may benefit from training in ways to gain most advantage from using the LMS.

Intrinsic and extrinsic motivation and locus of control were related to learning analytics. Students who were driven by mastery and felt in control were more likely to log on regularly to the LMS and to use more resources available to them. Those with an internal locus of control were also less interested in posts written by others. This makes sense, as part of mastery is to have a strong understanding of the unit content, and if you believe your actions are up to you, you may not necessarily need to pay attention to the questions and 
discussions of others. Extrinsically motivated students also were less likely to read posts on the discussion boards, suggesting they did not find value in improving their grade by doing so.

That is not to say that learning analytics on LMS use cannot provide pedagogically valuable information. As discussed by Whitmer (2013), there are differences between quality use of the LMS and quick use. A thoughtful discussion post is different from a quick reply, as is the quality of the time spent viewing resources. In this study, simply viewing the resources, replying or creating a discussion post, or logging on to the LMS was counted as activity. However, the amount of time spent viewing the resources, the amount of time spent online, or the thoughtfulness provided in a post was not taken into consideration. Future studies should take this into consideration. Further, students were a mix of both online-only students and blended learning students (who had access to face-to-face classes as well as to the LMS). It is worth exploring whether online students and blended learning students behave differently in the LMS, and whether: (1) LMS activity is more important for the online group only, and/or (2) LMS-related needs of these groups differ. A systematic review by Broadbent and Poon (2015) argued that online students use of the discussion boards was a better indicator of peer learning than more traditional measures. Further, perhaps for blended learning students LMS activity is less important because they could talk face-to-face with their tutor and other students.

Another limitation to consider is that no traditional correlates, such as intelligence, secondary school grades, or other previous grades were considered in this study. These more traditional predictors of academic achievement have been found to have positive, small to medium effects (Richardson et al., 2012; Robbins et al., 2004). Given that SE can be enhanced through mastery (prior achievement), it is likely that prior high achievement would impact positively, and prior low achievement would impact negatively on one's SE. While measuring intelligence and prior achievement was outside the scope of this paper, it is likely that these variables would add explanatory value to the model.

Finally, it is worth noting the timing of measurement may have also impacted findings. While the psychosocial measures were captured from Week 11 of semester in the present study, findings of the impact of SE and other predictors on academic performance may have differed if measured earlier, for example during the first weeks or midpoint of semester (Honicke \& Broadbent, 2016). Although beyond the scope of the present study, future research could explore the extent to which the relative importance of the currently tested predictors of performance differ as a function of when they were assessed within the teaching period.

In summary, the present student found that students who were academic confident, who did not lack motivation were more academic successful. While learning analytics were related to several psychosocial variables, LMS use within its self did not predict performance. A key challenge for learning analytics therefore is the capability to identify data that will contribute to improving learning models (Gray, McGuinness, Owende \& Carthy, 2014). While the present study does not lend support for using students’ behaviour as a prediction of academic success in its current state, this does not mean these metrics should be dismissed altogether. Learning analytics do have the potential to guide teaching practices to enhance learning in the online environment. If we are able to establish an easy to understand measure of online participation that we know enhances academic success, then teaching staff will be able to monitor and guide students in this practice and better understand what puts a student at risk.

\section{References}

Abesha, A. G. (2012). Effects of parenting styles, academic self efficacy, and achievement motivation on the academic achievement of university students (Doctoral dissertation). Edith Cowan University: Perth, Western Australia. Retrieved from http://ro.ecu.edu.au/theses/461

Ames, C., \& Archer, J. (1988). Achievement goals in the classroom: Students' learning strategies and motivation processes. Journal of Educational Psychology, 80(3), 260-267. http://dx.doi.org/10.1037/0022-0663.80.3.260

Bandura, A. (1991). Social cognitive theory of self-regulation. Organizational Behavior and Human Decision Processes, 50(2), 248-287. http://dx.doi.org/10.1016/0749-5978(91)90022-L

Bandura, A. (1997). Self-efficacy: The exercise of control. New York, NY: W. H. Freeman and Company. 
Beer, C., Clark, K., \& Jones, D. (2010). Indicators of engagement. Curriculum, technology \& transformation for an unknown future. Proceedings ASCILITE Sydney, 75-86. Retrieved from http://www.ascilite.org/conferences/sydney10/procs/Beer-full.pdf

Bong, M. (2005). Within-grade changes in Korean girls' motivation and perceptions of the learning environment across domains and achievement levels. Journal of Educational Psychology, 97(4), 656672. http://dx.doi.org/10.1037/0022-0663.97.4.656

Broadbent, J., \& Poon W. (2015). Self-regulated learning strategies \& academic achievement in online higher education learning environments: A systematic review. The Internet and Higher Education, 27(1), 1-13. 
performance over time. Journal of Educational Psychology, 92(2), 315-330.

http://dx.doi.org/10.1037/0022-0663.92.2.316

Harter, S. (1981). A new self-report scale of intrinsic versus extrinsic orientation in the classroom: Motivational and informational components. Developmental Psychology, 7(3), 300-12. http://dx.doi.org/10.1037/0012-1649.17.3.300

Honicke, T., \& Broadbent, J. (2016). The influence of academic self-efficacy on academic performance: A systematic review. Educational Research Review, 17(1), 63-84. http://dx.doi.org/10.1016/j.edurev.2015.11.002

Hu, L. T., \& Bentler, P. M. (1999). Cutoff criteria for fit indexes in covariance structure analysis: Conventional criteria versus new alternatives. Structural Equation Modeling: A Multidisciplinary Journal, 6(1), 1-55. http://dx.doi.org/10.1080/10705519909540118

Legault, L., Green-Demers, I., \& Pelletier, L. (2006). Why do high school students lack motivation in the classroom? Toward an understanding of academic amotivation and the role of social support. Journal of Educational Psychology, 98(3), 567. http://dx.doi.org/10.1037/0022-0663.98.3.567

Michinov, N., Brunot, S., Le Bohec, O., Juhel, J., \& Delaval, M. (2011). Procrastination, participation, and performance in online learning environments. Computers \& Education 56(1), 243-252. http://dx.doi.org/10.1016/j.compedu.2010.07.025

Middleton, M., \& Midgley, C. (1997). Avoiding the demonstrations of lack of ability: An underexplored aspect of goal theory. Journal of Educational Psychology, 89(4), 710-718. http://dx.doi.org/10.1037/0022-0663.89.4.710

Neuville, S., Frenay, M., \& Bourgeois, E. (2007). Task value, self-efficacy and goal orientations: Impact on self-regulated learning, choice and performance among university students. Psychologica Belgica, 47(1), 95-117. http://dx.doi.org/10.5334/pb-47-1-95

Perry, R. P. (2003). Perceived (academic) control and causal thinking in achievement settings. Canadian Psychologist, 44(4), 312-331. http://dx.doi.org/10.1037/h0086956

Perry, R. P., Hladkyj, S., Pekrun, R. H., \& Pelletier, S. T. (2001). Academic control and action control in the achievement of college students: A longitudinal field study. Journal of Educational Psychology, 93(4), 776-789. http://dx.doi.org/ 0.1037/0022-0663.93.4.776

Pintrich, P. R., Conley, A. M., \& Kemplar, T. M. (2004). Current issues in achievement goal theory and research. International Journal of Educational Research, 39(4), 319-337. http://dx.doi.org/10.1016/j.ijer.2004.06.002

Pintrich, P. R., \& Schunk, D. (1996). Motivation in education: Theory, research \& applications. Englewood Cliffs, NJ: Prentice-Hall

Richardson, M., Bond, R., \& Abraham, C. (2012). Psychological correlates of university students’ academic performance: A systematic review and meta-analysis. Psychological Bulletin, 138(2), 353387. http://dx.doi.org/10.1037/a0026838

Robbins, S. B., Lauver, K., Le, H., David, D., \& Langley, R. (2004). Do psychosocial and study skill factors predict college outcomes? A meta-analysis. Psychological Bulletin, 130(2), 261-288. http://dx.doi.org/10.1037/0033-2909.130.2.261

Rotter, J. B. (1966). Generalized expectancies for internal versus external control of reinforcement. Psychological Monographs: General and Applied, 80(1), 1-26. http://dx.doi.org/10.1037/h0092976

Schneider, W., Borkowski, J. G., Kurtz, B. E., \& Kerwin, K. (1986). Meta-memory and motivation a comparison of strategy use and performance in German and American children. Journal of CrossCultural Psychology, 17(3), 315-336. http://dx.doi.org/10.1177/0022002186017003005

Schonwetter, D., Perry, R. P., \& Struthers, C. W. (1993). Students' perceptions of control and success in the college classroom: Affects and achievement in different instruction conditions. Journal of Experimental Education, 61(3), 227-246. http://dx.doi.org/10.1080/00220973.1993.9943863

Seligman, M. E. P. (1975). Helplessness. San Francisco, CA: Freeman.

Society for Learning Analytics Research (2012). About. Retrieved from http://www.solaresearch.org/about/

Trice, A. (1985). An academic locus of control scale for college students. Perceptual and Motor Skills, 61(3), 1043-1046. http://dx.doi.org/10.2466/pms.1985.61.3f.1043

Turkmen, M. (2013). The relationships between gender, physical self-perception, sport experience, motivation orientations and academic success. International Journal of Academic Research, 5(5B), 66-72. http://dx.doi.org/10.7813/2075-4124.2013/5-5/B.10

Turner, E. A., Chandler, M., \& Heffer, R. W. (2009). Influence of parenting styles, achievement motivation, and self-efficacy on academic performance in college students. Journal of College Student Development, 50(3), 337-346. http://dx.doi.org/10.1353/csd.0.0073 
Vallerand, R. J., \& Bissonnette, R. (1992). Intrinsic, extrinsic, and amotivational styles as predictors of behaviour: A prospective study. Journal of Personality, 60(3), 599-620. http://dx.doi.org/10.1111/1467-6494.ep9209210978

Vallerand, R. J., Fortier, M. S., \& Guay, F. (1997). Self-determination and persistence in a real-life setting: Toward a motivational model of high school dropout. Journal of Personality and Social Psychology, 72, 1161-1176. http://dx.doi.org/10.1037/0022-3514.72.5.1161

Vanthournout, G., Gijbels, D., Coertjens, L., Donche, V., \& Van Petegem, P. (2012). Students' persistence and academic success in a first-year professional bachelor program: The influence of students' learning strategies and academic motivation. Education Research International,1(1), 1-10. http://dx.doi.org/10.1155/2012/152747

Whitmer, J. C. (2013). Logging on to improve achievement: evaluating the relationship between use of the learning management system, student characteristics, and academic achievement in a hybrid large enrollment undergraduate course. California, CA: University of California. Retrieved from http://www.editlib.org/p/121047/

Zimmerman, B. J., Bandura, A, \& Martinez-Pons, M. (1992). Self-Motivation for Academic Attainment: The Role of Self-Efficacy Beliefs and Personal Goal Setting. American Educational Research Journal, 29(3), 663-676. http://dx.doi.org/10.2307/1163261

Corresponding author: Dr Jaclyn Broadbent, jaclyn.broadbent@deakin.edu.au

Australasian Journal of Educational Technology (C) 2016.

Please cite as: Broadbent, J. (2016). Academic success is about self-efficacy rather than frequency of use of the learning management system. Australasian Journal of Educational Technology, 32(4), 38-49. 